\title{
Investigating a Role of Strategic Sourcing and Organizaiotnal Culture on Mitigating Risk in Supply Chain
}

\author{
Minkyun Kim*, Sangmi Chai**
}

\begin{abstract}
The main objective of this study is to investigate an impact of organizational culture on supply chain risk and strategic sourcing. It also examines the relationship between organizational culture and strategic sourcing. By collecting 159 survey responses from supply, executives and managers of U.S. manufacturing firms, it provides empirical evidence that organizational culture and strategic sourcing mitigate supply chain risks. Organizational culture also makes a positive impact on the implementation of strategic sourcing. This study emphasizes the importance of cultural impacts to supply executives and managers in supply chain risk management.
\end{abstract}

Key Words : Organizational culture, Strategic sourcing, Beliefs, Supply chain risk, Supply chain risk management

JEL classification : M11 \& M14

\footnotetext{
* Sogang Business School, Sogang University, Seoul, Korea. Email: minkyunkim@sogang.ac.kr First author, Minkyun Kim, Sogang Business School, Sogang University, 35 Baekbeom-ro, Mapo-gu, Seoul, Korea. Email: minkyunkim@sogang.ac.kr

** Ewha School of Business, Ewha Womans University, Seoul, Korea. Email: smchai@ewha.ac.kr Corresponding Author, Sangmi Chai, Ewha School of Business, Ewha Womans University, 52 Ewhayeodae-gil, Seodaemun-gu, Seoul, Korea. Email: smchai@ewha.ac.kr
} 


\section{Introduction:}

Managing risk in a supply chain has emerged as a critical issue in supply chain management due to an increased number of supply disruptions in the supply chain. Supply chain risk management (SCRM) is defined as the management of risk in the supply chain by collaborating with supply chain members in order to make sure of profitability and continuity (Norrman and Jansson 2004). SCRM has been receiving a great deal of attention from the industry as well as from scholars, because implementing SCRM provides supply chain members with the capability of reducing loss and damage generated by supply disruption risks (Blos, et al. 2009). Mitigating risk in the supply chain becomes a very complex issue for managers. Risk in the supply chain is generated from various areas, such as 1) operational risk within the firm, 2) supply chain risk in the supply chain, and 3) external risk of the supply chain (Christopher and Peck 2004). Among various sources of risk, this study focuses on the supply chain risk within the supply chain.

More importantly, managers are not capable of maintaining entire aspects of the supply chain when they take response actions against disruptions (Luhmann 1995). In addition, in current business trends, such as the increased use of outsourcing, the globalization of supply chains lead to more opportunities of increasing risks within the supply chain (Norrman and Jansson 2004).

In supply chain risk management, cultural factors can also make a significant impact on supply chain risk mitigation (Ritchie and Brindley 2007a). Risk management culture is also an important factor in reacting with the supply chain risk. Organizations with well-established culture on risk management recognize the significance of identifying supply chain risks and establishing plans on SCRM (Christopher, et al. 2011). Therefore, in order to establish risk mitigating strategies in the supply chain, this study investigates the impact of organizational culture on minimizing the supply chain risk. Strategic sourcing emphasizes the strategic role of purchasing, encourages effective internal coordination of the purchasing function with other functions as well as effective information sharing with suppliers, and assists supplier development and supply base management (Kocabasoglu and Suresh 2006). Strategic sourcing encourages collaboration with suppliers, enabling supply chain members to make a quick response toward supply chain disruptions. Thus, this research also examines the role of strategic sourcing as well as joint impact between strategic sourcing and organizational culture in mitigating the supply chain risk by investigating the relationship between organizational culture and strategic sourcing. 


\section{Theoretical Backgrounds and Literature Review}

\subsection{Theoretical Backgrounds}

Organizational culture has received much attention from researchers of supply chain risk management. However, research on the relationship between organizational culture and supply chain risk is relatively lacking. Thus, this research examines how organizational culture affects the supply chain risk. A general definition of the organizational culture is an indoctrination of mind that distinguishes human members of one group from other groups (Hofstede 1980). Organizational culture also refers to the beliefs and values which provide foundations for management systems, practices as well as members' behaviors (Denison, 1990). It is defined as "a pattern of basic assumptions by a group as it learns to deal with internal and external problems that have worked well and, therefore, to be taught to new group members as a correct way to perceive and think in relation to those problems" (Schein 1985; McDermott and Stock 1999). Obviously, organizational culture affects all aspects of organizations (Denison and Mishra 1995).

Although there are various approaches in discussing organizational culture, this study adopts Schein's approach as its theoretical background. Schein (Schein 1985; 1992) categorized three cultural aspects: artifacts, espoused values and basic underlying assumptions. Artifacts are behaviors that people can see, hear and feel when people experience unfamiliar culture. Artifacts are the focus of operations management research regarding organizational culture because they are visible. Espoused values become visible as people think that their considered beliefs are right, leading to their behaviors. These basic underlying assumptions are perceptions and feelings that become the basis of values and actions. This study considers the basic underlying assumptions to be customer orientation because supply managers' perceptions and feelings are based on their values and actions about serving customers. It also focuses on the espoused values of supply chain professionals in order to find out the cultural impact in their organizations. Because espoused values are regarded as the beliefs that members of the organization hold, they are not visible (Nahm, et al. 2004). By adopting Schein's approach in the organizational culture, this research focuses on the espoused values of supply and purchasing managers. Therefore, this study investigates managers' beliefs about supply chain risk management so that it can empirically confirm how managers' beliefs forming the organizational culture influence the supply chain risk. 


\subsection{Literature Review}

In the literature of supply chain management, prior studies point out the various benefits of implementing strategic sourcing in the supply chain. First of all, strategic sourcing is defined as a total process of purchasing input and managing relationships with suppliers, which leads to achieving the organization's long term objectives (Smeltzer, et al. 2003). Kocabasoglu and Suresh summarized these definitions with four essential dimensions of strategic souring: 1) the strategic role of purchasing, 2) internal coordination with purchasing function, 3) information sharing with suppliers and, 4) supplier development and supply management (Kocabasoglu and Suresh 2006).

Previous studies have also discussed many advantages of implementing strategic sourcing. In an earlier work, the research of Carr and Pearson (1999) confirmed that strategic purchasing has a positive impact on firms' financial performance, buyer-supplier relationships as well as on supplier evaluation systems. Carr and Smelzer (1999) also provided empirical evidence that indicated how strategic purchasing is positively associated with the firm's performance and thus, encouraged active cooperation with suppliers. The study of Narasimhan and Das (1999) demonstrated a positive relationship between strategic sourcing and manufacturing flexibility with meaningful insight into the significant role of strategic sourcing for improving the manufacturing flexibility. Adding to the above results, Narasimhan et al. (2001) found that purchasing competence has a significant relationship with total quality management and customer satisfaction (Narasimhan, et al. 2001).

Chen et al. (2004) utilized a different approach toward investigating the relationship between strategic purchasing and financial performance. In their research, strategic purchasing affects three important aspects positively in the supply chain: (1) communication with suppliers, (2) limiting the number of suppliers and the (3) development of long-term relationships with suppliers. Gonzalez-Benito (2007) examined the impact of both purchasing efficacy and purchasing strategic integration on commercial and financial performance, which turned out to be positively significant. Following suggestions that various theories need to be applied on strategic sourcing from the study of Shook, et al. 2009, this study applies the theory of organizational culture in order to examine how organizational culture affects the implementation of strategic sourcing. More importantly, this study adopts the theory of organizational culture as a theoretical background by investigating the cultural impact on the supply chain risk. 


\section{Research Model and Hypothesis}

Previous literature has suggested many strategies for mitigating the supply chain risk. Supply chain risk is defined as any risks for information, material and product flows from original suppliers to final customers (Juttner, et al. 2003). Various risks exist in supply chains. In this study, supply chain risk is narrowly focused on the risk in inbound perspective, meaning supply disruption risk. Previous literature presents many strategies for dealing with supply chain risks. The study of Braunscheidel and Suresh (2009) applied a supply chain agility approach in order to deal with supply chain disruptions. According to their study, supply chain agility and its antecedents provide organizations with the ability to respond quickly to changes and disruptions in the market.

The study of Chopra and Sodhi (2004) introduced seven strategies for mitigating risk: increasing capacity, acquiring redundant suppliers, increasing responsiveness, increasing inventory, increasing flexibility, pool or aggregate demand and increasing capability. The research of Christopher and Lee (2004) suggested three strategies for eliminating the spiraling supply chain risk: accurate and visible information, quickly informed and taking corrective actions. The research of Zhao et al. (2013) also suggested a positive role of supply chain integration to mitigate the impact of supply chain risk.

Craighead, et al. (2007) suggested two mitigation capabilities: recovery capability and warning capability. Recovery capability refers to the interactions between supply chain entities and the coordination of supply chain resources that speed up the recovery from disruptions. Warning capability refers to the interaction and coordination of supply chain resources in order to detect potential disruptions. Christopher and Peck (2004) pointed out the importance of risk assessment prior to setting up risk mitigating strategies. The study of Christopher and Peck then emphasized the importance of supply chain collaboration, such as information sharing and supply chain agility, in supply chain networks. In the study of Faisal, et al. (2006), supply chain risk management emphasized collaborative relationships, information sharing, strategic risk planning, and agility as one of the risk mitigating strategies in the supply chain. The research of Juttner, et al. (2003) also introduced four mitigating strategies of the supply chain: removing unreliable supply, contingency plans, cooperation with supply chain members, and flexibility

The study of Kleindorefer and Saad (2005) introduced ten principles of risk mitigating strategies: responsible for mitigating their own supply chain risks, a diversification, collaboration, prevention, avoiding extreme leanness and efficiency, contingency plans, collaborative information sharing, the risk assessment, agility and flexibility, and quality management. Responding to demand uncertainty generating from supply chain risk, global 
supply chain planning is considered as a solution (Lee and Jung 2013). By conducting a case study, Ericsson, Norman and Johnson (2004) presented two approaches of supply chain risk management strategies: collaboration with suppliers and a proactive approach toward the supply chain risk. A comprehensive supply chain risk management approach has been crucially pointed out for effective prevention and risk mitigation against supply disruptions (Blome and Schoenherr 2011). In the transportation in global supply chain, risk management has also been emphasized by finding a optimal point of trade facilitation and operational safety (Froufe et al. 2014).

Prior studies have suggested various risk mitigating strategies within the supply chain. Based on the previous literature's recommendations, these strategies have come from solutions, such as collaboration and information sharing, with suppliers and flexibility in the supply chain. Therefore, this study introduces strategic sourcing, as one of the supply chain practices, in order to mitigate supply chain risks. As we discussed in the above studies, risk mitigating strategies emphasize the significance of information sharing, supplier development, flexibility and internal coordination. One definition of strategic sourcing addressed collaboration with suppliers, as it was defined as the use of supplier capabilities in establishing incorporated relationships in the process of manufacturing (Narasimhan and Das 1999). The definition also mentioned that strategic sourcing should consider systematic risk for assisting the buying decision-making process (Sislian and Satir 2000). It has pointed out the significance of managing supplier relationships, as they defined it as "a systematic and comprehensive process of acquiring inputs as well as managing supplier relations in a manner that achieves value in obtaining the organization's long term objectives" (Smeltzer, et al. 2003).

Based on these definitions, strategic sourcing has two main aspects and four dimensions. The role of purchasing within the firm represents two dimensions, which are a strategic role on the status of purchasing and an effective internal coordination of purchasing with other functions of the firm. The building of effective relationships represents two dimensions, information sharing with suppliers and development of suppliers (Kocabasoglu and Suresh 2006). Strategic sourcing enables buyers to develop relationships with suppliers through information sharing as well as through internal integration. This study anticipates strategic sourcing to negatively affect supply chain risks. Therefore, this study proposes hypothesis 1 :

H1: Strategic sourcing mitigates supply chain risks.

More importantly, this study considers organizational culture in the research framework of supply chain risk management. Although cultural impact is considered as a significant factor for supply chain risk management, these cultural impacts have not been 
fully investigated yet. It is found that cultural factors had a significant impact on supply chain agility and flexibility, which facilitate supply chain risk mitigation (Ritchie and Brindley 2007b). The research of Braunscheidel and Suresh (2009) also emphasized the importance of cultural impacts. In their study, they divided the cultural aspects into market orientation and learning orientation. Market orientation culture was defined as an organizational culture that could create superior values for customers, while learning orientation culture was defined as an organizational culture that looked for learning for improvement and attempted to create values for an organization (Braunscheidel and Suresh 2009). Unlike their studies, this study investigates how an underlying level of beliefs in an organizational culture affects managers' perceptions toward supply chain risks as well as strategic sourcing, which is one of the supply chain practices.

The implementations of supply chain practices, such as strategic sourcing, are influenced by organizational cultures. Individuals in organizations who have different beliefs and values will adopt these practices differently. It has been proposed that organizational cultures are also associated with the benefits of magnitude, flexibility and speed of response obtained by the implementation of advanced manufacturing technology (Zammuto and O'Connor 1992). The study of McDermott and Stock (1999) empirically tested Zammuto and O'Connor's propositions. They found that organizational culture and advanced manufacturing technology implementation are closely associated with each other. Their research results revealed that group culture correlated positively with advanced manufacturing technology outcomes; however, development culture negatively correlated with advanced manufacturing technology.

In addition, externally oriented culture positively correlated with competitive benefits (McDermott and Stock 1999). Organizational cultures had a significant relationship with leadership, strategic planning, customer focus, information analysis, people and process management in total quality management practices (Prajogo and McDermott 2005). Beliefs in the value of investment in production, group work, external orientation, control and integration are associated with time-based manufacturing practices (Nahm et al. 2004).

Organizational culture affects the supply chain as well as the strategic sourcing since the supply chain practice because it makes an impact on managers' perceptions and behaviors toward supply chain and supply chain practices. Thus, this research assumes that organizational culture based on supply and purchasing managers' beliefs influences the attitude toward both strategic sourcing and supply chain risks. It focuses on managers' beliefs on working with others and on integrating with suppliers since collaboration, information sharing with suppliers, is suggested as a solution for mitigating the supply chain risk. Beliefs on making decisions that are global are added due to applying the context of the global supply chain. Because this study focuses on the espoused values from 
the organizational culture, managers' attitudes and beliefs relating to supply chain risks are very crucial factors on how they perceive and react toward supply chain risks. Therefore, this study proposes hypothesis 2 and 3 :

H2: Organizational cultures mitigate supply chain risks.

H3: Organizational cultures are positively associated with strategic sourcing.

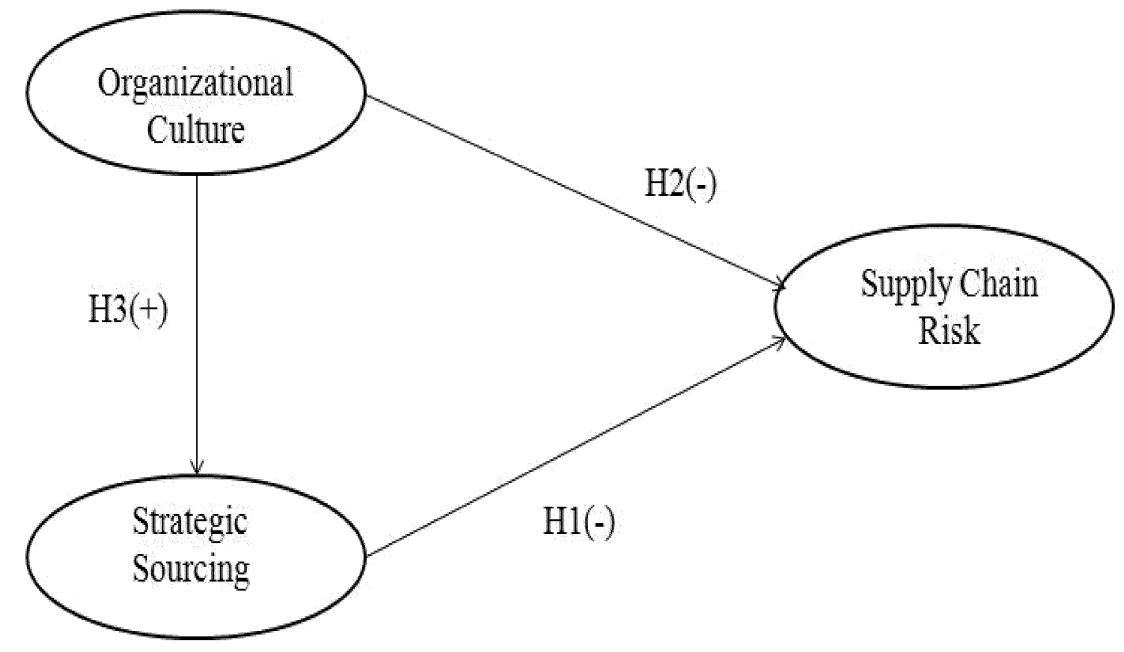

Figure 1.

Research Model

\section{Methodology}

This study utilized survey questionnaires in order to collect the data. It developed instruments for survey measurements based on previous literature. The survey items as well as references are listed in table 1. Organizational culture is measured by nine items which indicated supply and purchasing managers' beliefs on working with others, making decisions that are global, and integrating with suppliers. Strategic sourcing is measured by five items regarding the role of purchasing. Supply chain risk is measured by 6 items representing the disruption risk in the supply chain. In order to increase the quality of the survey instruments, the survey was reviewed by a group of experts in the field of supply chain management. Throughout the interview, they went over the survey and provided feedback on how well the survey items were measured. Their recommendations were incorporated and the instruments were modified based on their feedback by rewording items in order to increase the clarity as well as to make them easier to answer. Then, a pilot 
study was properly conducted with a small sample. A total of 32 responses from supply and purchasing managers were collected for the pilot study.

After reflecting upon all of the feedbacks and comments on the survey items, executives and supply and purchasing managers in U.S. firms were contacted via e-mail, and they participated in the web version survey. The e-mail announcement of the survey was sent to members, comprising a total of 622 members. One hundred fifty-nine members participated in the survey, making the response rate $25.56 \%$. Thus, a total of one hundred fifty-two surveys except for seven incomplete responses were used for data analysis. The respondents were mainly from manufacturing industries. After collecting all of the surveys, this research utilized the partial least squares (PLS) technique for data analysis.

\section{Results}

\subsection{Measurement Model}

This study adopted all survey items from previously published literature in order to increase the reliability; all items were assessed using the seven-point Likert scale. To establish strong reliability of measurement items, factor loadings of all indicators of the constructs have had to be greater than 0.7 (Fornell and Larker 1981). It also used Cronbach's a for assessing reliability. All factor loadings of measurement indicators showed acceptable reliability and all Cronbach's a score were greater than 0.7 , presenting strong reliability. This research used the composite reliability (CR) and the average variance extracted (AVE) for conducting a convergent validity test. In order to present good internal consistency, the value of composite reliability needs to be greater than 0.7 (Hulland 1999). In addition, AVE, which is defined as the proportion of average variance between constructs and indicator variables, should be above 0.5 (Chin 1998). Using the PLS, this research also performed a factory analysis on the survey items. All loadings are above 0.7 , which is acceptable (Chin 1998), and no significant cross loadings were found, which provides evidence of scale unidimensionality. The factor analysis results are presented in table 3. All measures of the factor loadings, Cronbach's a, CR and AVE are presented in table 1. Following the suggestions of Fornell and Larker (1981), this study accessed the discriminant validity by confirming that the square root of AVE should be greater than the correlations of the variables. In table 2, the value of the diagonal elements appears to be greater than those of the off-diagonal elements (Fornell and Larker 1981; Hulland 1999). 


\section{Table 1.}

Constructs Measurement Summary: Reliability

\begin{tabular}{|c|c|}
\hline Item Description (Reliability, Cronbach's a, CR, AVE) & $\begin{array}{c}\text { Factor } \\
\text { Loadings }\end{array}$ \\
\hline \multicolumn{2}{|l|}{$\begin{array}{l}\text { Organizational culture (anchors: } 1=\text { strongly disagree to } 7=\text { strongly agree; Nahm, } \\
\text { Voderemmbse, and Koufteros 2004), Cronbach's a }=0.937, \mathrm{CR}=0.953, \mathrm{AVE}=0.885\end{array}$} \\
\hline 1. Functional departments should work together as a team. & 0.831 \\
\hline $\begin{array}{l}\text { 2. Employees from one department should work with employees from other } \\
\text { departments. }\end{array}$ & 0.899 \\
\hline 3. Employees should work together as a team. & 0.912 \\
\hline 4. Departmental managers should make decisions that benefit the whole company. & 0.864 \\
\hline 5. When making decisions, the overall effects of a decision should be considered. & 0.897 \\
\hline 6. Decisions should be based on overall company objectives. & 0.802 \\
\hline 7. Our suppliers can be part of our success in our business. & 0.855 \\
\hline 8. Our suppliers are strategic partners in building up our competitive capabilities. & 0.806 \\
\hline 9. The best suppliers are the ones who enable us to provide value to customers. & 0.844 \\
\hline \multicolumn{2}{|l|}{$\begin{array}{l}\text { Strategic Sourcing(anchors: } 1=\text { stronglydisagreeto } 7=\text { stronglyagree;Kocabasogluand } \\
\text { Suresh2006,Chen,PaulrajandLado2004),Cronbach'sa=0.877,CR=0.910, } \\
\text { AVE }=0.718\end{array}$} \\
\hline 1. Purchasing is included in the firm's strategic planning process. & 0.849 \\
\hline 2. The purchasing function has good knowledge of the firm's strategic goals. & 0.838 \\
\hline $\begin{array}{l}\text { 3. Purchasing performance is measured in terms of its contributions to the firm's } \\
\text { success. }\end{array}$ & 0.904 \\
\hline $\begin{array}{l}\text { 4. The purchasing professionals' development focuses on elements of the } \\
\text { competitive strategy. }\end{array}$ & 0.855 \\
\hline 5. The purchasing department plays an integrative role in the purchasing function. & 0.889 \\
\hline \multicolumn{2}{|l|}{$\begin{array}{l}\text { Supply Chain Risk (anchors: } 1=\text { extremely low to } 7=\text { extremely high; Ellis, Henry } \\
\text { and Shockley 2010), Cronbach's a }=0.875, \mathrm{CR}=0.923 \text {, AVE }=0.736\end{array}$} \\
\hline $\begin{array}{l}\text { 1. It is highly unlikely that we will experience an interruption in the supplies from } \\
\text { our suppliers. }\end{array}$ & 0.915 \\
\hline 2. There is a high probability that our suppliers will fail to provide supplies to us. & 0.887 \\
\hline $\begin{array}{l}\text { 3. We worry that suppliers may not provide supplies as specified within our } \\
\text { purchase agreement. }\end{array}$ & 0.824 \\
\hline $\begin{array}{l}\text { 4. An interruption in the supplies from our suppliers would have severe negative } \\
\text { financial consequences for our business. }\end{array}$ & 0.802 \\
\hline $\begin{array}{l}\text { 5. Suppliers' inability to provide supplies would jeopardize our business } \\
\text { performance Information system sophistication. }\end{array}$ & 0.866 \\
\hline $\begin{array}{l}\text { 6. We would incur significant costs and/or losses in revenue if our suppliers failed } \\
\text { to provide legal liabilities of the supplies. }\end{array}$ & 0.915 \\
\hline
\end{tabular}


Organizaiotnal Culture on Mitigating Risk in Supply Chain

Table 2.

Correlation Matrix: Discriminant Validity

\begin{tabular}{c|c|c|c}
\hline Variables & OC & SS & SCR \\
\hline OC & $(0.941)$ & & \\
\hline SS & 0.195 & $(0.847)$ & \\
\hline SCR & 0.339 & 0.114 & $(0.858)$ \\
\hline
\end{tabular}

OC : Organizational Culture, SS: Strategic Sourcing, SCR: Supply Chain Risk

- The number in parenthesis is the square root of AVE.

Table 3.

Factor Analysis Results

\begin{tabular}{c|c|c|c}
\hline & OC & SS & SCR \\
\hline OC1 & $\mathbf{0 . 8 3 1}$ & 0.212 & 0.031 \\
\hline OC2 & $\mathbf{0 . 8 9 9}$ & 0.233 & 0.301 \\
\hline OC3 & $\mathbf{0 . 9 1 2}$ & 0.378 & 0.401 \\
\hline OC4 & $\mathbf{0 . 8 6 4}$ & 0.002 & 0.288 \\
\hline OC5 & $\mathbf{0 . 8 9 7}$ & 0.001 & 0.369 \\
\hline OC6 & $\mathbf{0 . 8 0 2}$ & 0.256 & 0.174 \\
\hline OC7 & $\mathbf{0 . 8 5 5}$ & 0.399 & 0.186 \\
\hline OC8 & $\mathbf{0 . 8 0 6}$ & 0.471 & 0.233 \\
\hline OC9 & $\mathbf{0 . 8 4 4}$ & -0.051 & 0.258 \\
\hline SS1 & 0.147 & $\mathbf{0 . 8 4 9}$ & -0.236 \\
\hline SS2 & 0.159 & $\mathbf{0 . 8 3 8}$ & -0.214 \\
\hline SS3 & -0.210 & $\mathbf{0 . 9 0 4}$ & -0.121 \\
\hline SS4 & 0.317 & $\mathbf{0 . 8 5 5}$ & 0.241 \\
\hline SS5 & 0.365 & $\mathbf{0 . 8 8 9}$ & 0.336 \\
\hline SCR1 & 0.225 & 0.333 & $\mathbf{0 . 9 1 5}$ \\
\hline SCR2 & 0.028 & 0.223 & $\mathbf{0 . 8 8 7}$ \\
\hline SCR3 & 0.182 & 0.340 & $\mathbf{0 . 8 2 4}$ \\
\hline SCR4 & 0.339 & 0.321 & $\mathbf{0 . 8 0 2}$ \\
\hline SCR5 & 0.384 & 0.146 & $\mathbf{0 . 8 6 6}$ \\
\hline SCR6 & 0.222 & 0.100 & $\mathbf{0 . 9 1 5}$ \\
\hline & & &
\end{tabular}

\subsection{Main Effects}

The partial least squares (PLS) technique is applied in order to investigate the structural model. A bootstrap resampling procedure was conducted to examine the stability 
of the estimates (Chin et al. 2003) and to develop robust confidence intervals (Chin 1998). The results of the study confirm that strategic sourcing negatively affects supply chain risk, supporting hypothesis 1: strategic sourcing mitigates supply chain risks. The results indicate that there is statistical significance to this negative relationship, with a path coefficient of -0.245 and a t-score of 2.89 at the 0.01 level of significance. The results also show that organizational culture has a negative relationship with supply chain risks, which supports hypothesis 2: organizational cultures mitigate supply chain risks. With a path coefficient of -0.228 and a t-score of 2.65 at the 0.01 level, the research results show that there is a statically significant negative relationship between organizational culture and supply chain risks. Hypothesis 3 , which stated that organizational culture is positively associated with strategic sourcing, was also supported by our research results, a path coefficient of 0.211 and a t-score of 2.64 at the 0.01 level of significance, as organizational culture has a positive impact on implementing strategic sourcing. Figure 2 describes our research results.

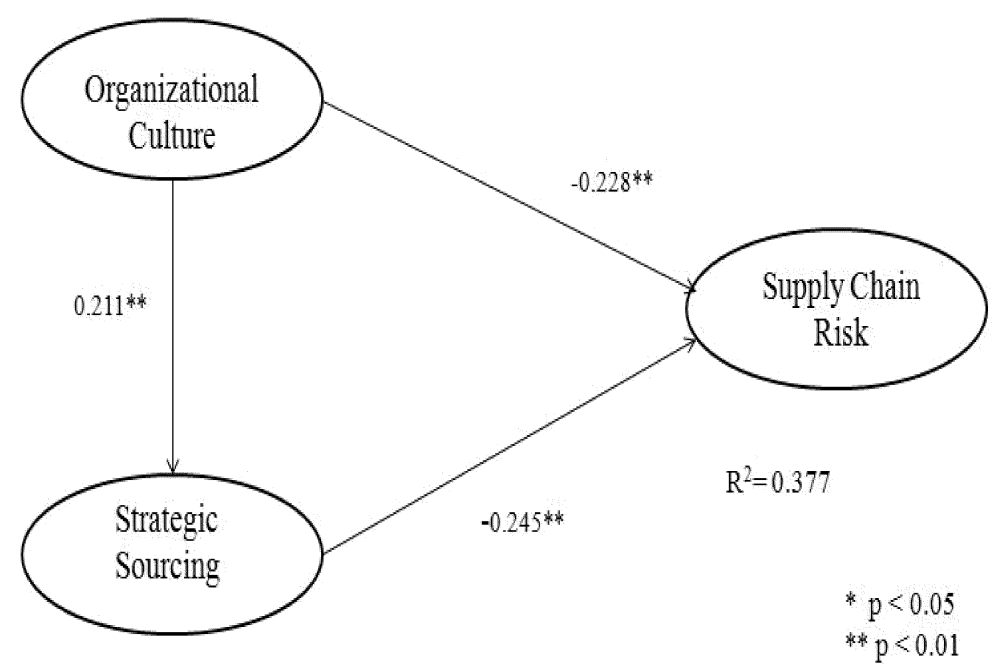

Figure 2.

Research Results

\section{Discussion and Conclusions}

Depending on the organizational culture theory, this study investigates how organizational culture affects supply chain risks and strategic sourcing. In addition, it also 
examines how strategic sourcing can be effectively implemented to mitigate supply chain risks. This research makes meaningful contributions for both academics and practitioners. Although there was a lack of empirical literature on supply chain risk management, this study empirically demonstrates that establishing positive organizational culture toward working with others and implementing strategic sourcing mitigate supply chain risks. Moreover, this study contributes to filling the gap by empirically validating the impact of organizational culture and strategic sourcing in SCRM. More importantly, previous literature introduces various risk mitigating strategies in SCRM. However, all of the strategies are solutions, suggestions and recommendations, and only a very few studies attempt to conduct an empirical validation (Juttner, et al. 2003). It provides empirical evidences regarding mitigating factors in supply chain risk. This study also provides managerial implications that can be utilized by purchasing and supply managers as field solutions and setting up strategies on mitigating supply chain risk

Although previous literature pointed out the significance of organizational culture in supply chain risk management, there was a lack of prior literature that set up the relationship between organizational culture and supply chain risks (Ritchie and Brindley 2007b; Braunscheidel and Suresh 2009). Thus, this research attempts to investigate the association between organizational culture and supply chain risks. By adopting Schein's approach of espoused values and beliefs of purchasing and supply managers, this study empirically confirmed that purchasing and supply managers' beliefs on working with others, beliefs on making decisions that are global and beliefs on integrating with suppliers mitigate supply chain risks; further, those managers' beliefs positively influence the implementation of strategic sourcing. This research adopted a theoretical framework of organizational culture in the context of supply chain risk management. Therefore, it contributes to providing empirical results that support the organizational culture theory in the context of supply chain risk management. This research also contributes that managers need to recognize the importance of organizational culture in establishing a risk mitigating strategy and in implementing supply chain practices. Specifically, when managers set up strategies in supply chain management, they should consider their own organizational culture for the success of risk mitigation and the implementation of supply chain practices. If managers have strong beliefs on working with others, making decisions that are global and integrating with suppliers, their beliefs encourage supply and purchasing managers to collaborate with their suppliers resulting in positive impacts on mitigating supply chain risk and implementing strategic sourcing. Therefore, motivating supply and purchasing managers in working as a team, integrating with suppliers and making a global decision would lead to positive impacts on mitigating supply chain risk and integrating procurement practices in firm's strategy. 
The research results empirically support that strategic sourcing decreases supply chain risks. This research measured supply chain risks in both of the following dimensions: probability and magnitude of supply chain disruption risk. Strategic sourcing is very effective in minimizing the probability and magnitude of the supply chain disruption risk largely for the following reason: strategic sourcing enables buyer firms to interact very close with suppliers in order to help them develop. Thus, strategic sourcing improves suppliers' ability to provide high quality supplies to buyers without any disruptions. Even if supply disruptions occur, supplier and buyers work together to minimize the magnitude of supply chain disruption so that they can reduce the damage to the supply chain. Due to this reason, supply and purchasing managers consider strategic sourcing to be an effective supply chain practice for mitigating supply chain risks. Prior literature showed that implementing strategic sourcing results improves a firm's performance (Carr and Pearson 1999; Das and Narasimhan 2000; Narasimhan and Das 2001; Chen, et al. 2004). The benefits of implementing strategic sourcing not only improved the firm's performance but also mitigated the risk in the supply chain. Adding to the previous research, implementing strategic sourcing leads not only to the enhancement of the firm's performance but also to the mitigation of supply chain risks. Many benefits of implementing strategic sourcing encourage firms to adopt strategic sourcing in order to gain competitive advantages. It offers managerial implications that strategic sourcing is one of the effective supply chain practices in mitigating supply chain risks. Thus, this research provided different directions on how managers can implement and facilitate strategic sourcing.

This research can be extended with different approaches. First, the research model in this study can be examined in the service industry, such as the health care and financial industry because this study focuses on manufacturing industry. Second, a future study should consider the cultural impact of other countries. This research model in supply chain risk management can also be applied in China and in the USA. Finally, various business characteristics can be considered in this research model by investigating the moderating effects on the relationship among constructs.

\section{Acknowledgements}

This work is supported by the Sogang University Research Grant of 2011 (201110053.01) 


\section{References}

Blome, C., Schoenherr, T. (2011) "Supply chain risk management in financial crisis - A multiple case-study approach," International Journal of Production Economics, $134,43-57$

Blos, M. F., Quaddus, M., Wee, H.M., Watanabe, K. (2009) "Supply chain risk management (SCRM): a case study on the automotive and electronic industries in Brazil," Supply Chain Management: An International, 14, 247-252

Braunscheidel, M. J., Suresh, N. C. (2009) "The Organizational Antecedents of a Firm's Supply Chain Agility for Risk Mitigation and Response," Journal of Operations Management, 27, 119-140

Carr, A. S., Pearson, J. N. (1999) "Strategically managed buyer-supplier relationships and performance outcomes," Journal of Operations Management, 17, 497-519

Carr, A. S., Smeltzer, L. R. (1999) "The relationship of strategic purchasing to supply chain management," European Journal of Purchasing \& Supply Management, 5, 43-51

Chen, I. J., Paulraj, A., Lado, A. A. (2004) "Strategic purchasing, supply management, and firm performance," Journal of Operations Management, 22, 505-523

Chin, W. W. (1998). The PLS approach to structural equation modeling in Modern methods for business research. Methodology for business and management (Ed.) Marcoulides, George A. Lawrence Erlbaum Associates Publishers, Mahwah, NJ

Chin, W. W., Marcolin, B., L., Newsted, P. R. (2003) “A partial least squres latent variable modeling approach for measuring interaction effects: Results from a Monte Carlos simulation study and an electronic mail emotion/adoption study," Information Systems Research, 14, 189-217

Chopra, S., Sodhi, M. S. (2004) "Managing Risk to Avoid Supply-Chain Breakdown," Sloan Management Review, 46, 53-61 
Christopher, M., Carlos Mena, C. Khan, O., Yurt, O. (2011) "Approaches to managing global sourcing risk," Supply Chain Management: An International, 16, 67-81

Christopher, M., Lee, H. (2004) "Mitigating supply chain risk through improved confidence," International Journal of Physical Distribution \& Logistics Management, 34, 388-396

Christopher, M., Peck, H. (2004) "Building the Resilient Supply Chain," International Journal of Logistics Management, 15, 1-13

Craighead, C. W. Blackhurst, J.M., Rungtusanatham, J., Handfield, R.B. (2007) "The Severity of Supply Chain Disruptions: Design Characteristics and Mitigation Capabilities," Decision Sciences, 38, 131-156

Das, A., Narasimhan, R. (2000) "Purchasing competence and its relationship with manufacturing performance," Journal of Supply Chain Management, 36, 17-29

Denison, D. R. (1990) Corporate Culture and Organizational Effectiveness, John Wiley \& Sons, New York, NY

Denison, D. R., Mishra, A. K. (1995) "Toward a theory of organizational culture and effectiveness," Organization Science, 6, 204-223

Denison, D. R., Spreitzer, G. M. (1991) "Organizational culture and organizational development: a competing values approach," Research in Organizational Change and Development, 5, 1-21

Ellis, S.C., Henry, R.M..Shockley, J. (2010) "Buyer perceptions of supply disruption risk: A behavirol view and emprical assessment," Journal of Operations Management, $28,34-46$

Faisal, M. N., Banwet, D. K., Shankar, R. (2006) "Supply chain risk mitigation: modeling the enablers," Business Process Management Journal, 12, 535-552

Falk, R. F., Miller, N. B. (1992) A primer for soft modeling, University of Akron Press, Akron, $\mathrm{OH}$ 
Fornell, C., Larker, D. F. (1981) "Evaluating structural equation models with unobservable variables and measurement error," Journal of Marketing Research, 18, 39-50

Froufe, S., Gningue, M., Fredouet, C.H.(2014) "Expertise modeling and transportation risk management: An application to contrainer transportation security risk maangement," Journal of International Logistics and Trade, 12, 75-97

Gonzalez-Benito, J. (2007) "A theory of purchasing's contribution to business performance," Journal of Operations Management, 25, 901-917

Haenlein, M., Kaplan, A. M. (2004) “A Beginner's Guide to Partial Least Squares Analysis," Understanding Statistics, 3, 283 - 297

Hofstede, G. (1980) Cultures Consequences: International Differences in Work-Related Values, Sage, Beverly Hills, CA

Hulland, J. (1999) "Use of partial least squares (PLS) in strategic management research: A review of four recent studies," Strategic Management Journal, 20, 195-204

Juttner, U., Peck, H., Christopher, M. (2003) "Supply chain risk management: outlining an agenda for future research," International Journal of Logistics: Research \& Applications, 6, 197-210

Kleindorfer, P. R., Saad, G. H. (2005) "Managing Disruption Risks in Supply Chains," Production and Operations Management, 14, 53-68

Kocabasoglu, C., Suresh, N. C. (2006) "Strategic sourcing: An empirical investigation of the concept and its practices in U.S. manufacturing firms," Journal of Supply Chain Management, 42, 4-16

Lee, H, Jung, H. (2013) "Scenario based global supply chain proceess considering demand uncertainty," Journal of International Logistics and Trade, 11, 67-86

Luhmann, N. (1995) Social Systems, Stanford University Press, Stanford, CA 
McDermott, C. M., Stock, G. N. (1999) "Organizational culture and advanced manufacturing technology implementation," Journal of Operations Management, $17,521-533$

Nahm, A. Y., Vonderembse, M. A., Koufteros, X. A. (2004) "The Impact of Organizational Culture on Time-Based Manufacturing and Performance," Decision Sciences, 35, $579-607$

Narasimhan, R., Das, A. (1999) "An Empirical Investigation of the Contribution of Strategic Sourcing to Manufacturing Flexibilities and Performance," Decision Sciences, 30, 683-718

Narasimhan, R., Das, A. (2001) "The impact of purchasing integration and practices on manufacturing performance," Journal of Operations Management, 19, 593-609

Narasimhan, R., Jayaram, J., Das, A. (2001) "An empirical examination of the underlying dimensions of purchasing competence," Production \& Operations Management, 10, $1-15$

Norrman, A., Jansson, U. (2004) "Ericsson's proactive supply chain risk management approach after a serious sub-supplier accident," International Journal of Physical Distribution \& Logistics Management, 34, 434-456

Prajogo, D. I., McDermott, C. M. (2005) "The relationship between total quality management practices and organizational culture," International Journal of Operations \& Production Management, 25, 1101-1122

Ritchie, B., Brindley, C. (2007a) "An emergent framework for supply chain risk management and performance measurement," Journal of the Operational Research Society, 58, 1398-1411

Ritchie, B., Brindley, C. (2007b) "Supply chain risk management and performance: A guiding framework for future development," International Journal of Operations \& Production Management, 27, 303-322.

Schein, E. H. (1985) Organizational culture and leadership, Jossey-Bass, San Francisco, CA 
Schein, E. H. (1992) Organizational culture and leadership, 2nd Edition, Jossey-Bass, San Francisco, CA

Shook, C. L., Adams, G.L., Ketchen, D.J., Craighead, C.W. (2009) "Towards a "theoretical toolbox" for strategic sourcing," Supply Chain Management: An International, 14, 3-10

Sislian, E., Satir, A. (2000) "Strategic sourcing: A framework and a case study," Journal of Supply Chain Management, 36, 4-11

Smeltzer, L., Manship, J. A., Rossetti, C. L. (2003) "An analysis of the integration of strategic sourcing and negotiation planning," Journal of Supply Chain Management, $39,16-25$

Zammuto, R. F., O'Connor, E. J. (1992) "Gaining advanced manufactruing technologies' benefits: The roles of organization design and culture," Academy of Management Review, 17, 701-728

Zhao, L., Huo, B., Sun, L., Zhao, X.(2013) "The impact of supply chain risk on supply chain integration and company performance: a global investigation," Supply Chain Management: An International, 18, 115-131 